\title{
Identification of genetic heterogeneity in Refsum's disease
}

\author{
Anthony S Wierzbicki ${ }^{1,2}$, John Mitchell ${ }^{3}$, Michelle Lambert-Hammill ${ }^{1}$, Margaret Hancock ${ }^{2}$, \\ Juliet Greenwood ${ }^{3}$, Margaret C Sidey ${ }^{4}$, Jacqueline de Belleroche ${ }^{3}$ and F Brian Gibberd ${ }^{4}$
}

\begin{abstract}
${ }^{1}$ Department of Chemical Pathology, King's Guy's \& St Thomas' Medical School, King' College; ${ }^{2}$ Department of Chemical Pathology, Imperial College of Science, Technology and M edicine, Chelsea \& Westminster Hospital; ${ }^{3}$ Department of N euromuscular Disease, Imperial College of Science, Technology and M edicine, Charing Cross Hospital; ${ }^{4}$ Department of Clinical Pharmacology and Therapeutics, Imperial College of Science, Technology and Medicine, Chelsea \& Westminster Hospital, London, UK
\end{abstract}

Refsum's disease (MIM 266500) is a recessive disorder characterised by defective peroxisomal alpha-oxidation of phytanic acid. A Refsum's disease gene, phytanoyl-CoA hydroxylase (PAHX), has been localised to chromosome 10p13 between the markers D10S226-D10S223. This study investigated whether all cases of Refsum's disease were linked with chromosome 10p13. Eight genetically informative families comprising 92 individuals including 17 living patients with a Refsum's disease phenotype and initial plasma phytanic acid $>200 \mu \mathrm{mol} / \mathrm{L}$ were recruited. Linkage to the 10pter-10p11.2 region was investigated using a panel of eight dinucleotide repeat markers. Linkage analysis of this phenotypically identical cohort suggested that Refsum's disease was genetically heterogeneous $\left(Z_{\max }=5.28, \alpha=0.45\right)$. Two subgroups were identified. One group of four families with eight affected individuals had a maximum multipoint lod score for linkage of 3.89 in the region D10S547 to D10S191, whilst in another three families with nine affected individuals linkage to this region was definitely excluded. Our results show that Refsum's disease is genetically heterogeneous, with up to $55 \%$ of cases not being linked to the PAHX gene locus at D10S547 to D10S223. This suggests that Refsum's disease, in common with other peroxisomal 'diseases', may be more accurately described as a heterogeneous syndrome. European Journal of Human Genetics (2000) 8, 649-651.

\section{Keywords: Refsum's disease; phytanic acid; linkage; heterogeneity}

\section{Introduction}

Refsum's disease (MIM 266500) is an autosomal recessive disorder characterised by defective peroxisomal alpha-oxidation of phytanic acid leading to presentation in adolescence with retinitis pigmentosa which progresses to eventual blindness. Other features with variable penetrance include anosmia, deafness, sensory neuropathy, ichthyosis, ataxia, peripheral skeletal or limb dysmorphology and cardiomyopathy. ${ }^{1}$ A Refsum's disease gene, phytanoyl-CoA hydroxylase (PAHX), has been localised to chromosome10p13 between the markers D10S226-D10S4223 near D10S191. ${ }^{2,3}$ Mutations

Correspondence: Dr AS Wierzbicki, Department of Chemical Pathology, St Thomas' Hospital, Lambeth Palace Road, London SE1 7EH, UK. Tel: +442079289292 × 2027;

Fax: +44 207928 4226; E-mail: Anthony.Wierzbicki@kcl.ac.uk

Received 5 July 1999; revised 6 April 2000; accepted 27 April 2000 in PAHX have been identified in 13 cases of Refsum's disease. ${ }^{4}$ This study investigated whether all cases of Refsum's disease were linked with chromosome10p13.

\section{Materials and methods}

Eight families comprising 92 individuals including 17 living patients with Refsum's disease were recruited, with ethical consent, from a specialist clinic. All the affected patients had the classic clinical features of Refsum's disease of retinitis pigmentosa, anosmia, sensory neuropathy and ataxia. All had visual deterioration after age 12 with initial night blindness and later developed other clinical signs. Deafness and short fifth metacarpals/metatarsals were present in $70 \%$ and $50 \%$ of cases, respectively, on presentation. All had an initial plasma phytanic acid concentrations $>200 \mu \mathrm{mol} / \mathrm{L}$ 
(referencelimit $<30 \mu \mathrm{mol} / \mathrm{L}$ ). All unaffected family members were reviewed and none had features of classical Refsum's disease. Their plasma phytanic acid concentrations were all $<15 \mu \mathrm{mol} / \mathrm{L}$. Family 7 was consanguineous by reason of a first cousin marriage. EDTA blood samples were obtained from 50 living individuals in these families including all except two deceased affected individuals and two unaffected individuals. A panel of eight fluorescein-labelled dinucleotide repeat markers spanning 10pter-10p11.2 (Perkin Elmer, UK) was amplified from patient Iymphocyte DNA by polymerase chain reaction and typed on a $\mathrm{ABI} 310$ analyser with Geneamp software (Perkin-Elmer Ltd, UK). Fluorescent scans were automatically scored and allele typings were confirmed by two independent observers blinded to the clinical data. Any markers showing ambiguous allele sizes were re-run. The final data was analysed by standard techniques using the GENEHUNTER linkage analysis program ${ }^{5}$ assuming complete penetrance for a recessive disorder and a mutation rate of $10^{-5}$. The allele frequency for the Refsum's disease trait was assumed as 0.001 based on the prevalence of Refsum's disease of $10^{-6}$ in the UK. Primer sequences, allele frequencies and distances for chromosome10 markers were taken from computerised database sources (www.genlink.wustl.edu). Heterogeneity in inheritance and admixture were assessed using the computer program HOMOG. ${ }^{6}$

\section{Results}

Statistical analysis of the two point linkage data for the families is shown in Table1. Initial analysis revealed no linkage of Refsum's disease in the overall cohort to chromosome10. Analysis for genetic heterogeneity allowing for admixture was conducted using the program HOMOG giving a result of $Z_{\max }=5.284$ at a distance $(\theta)$ of 0.25 from D10S249, and a proportion of linked families $(\alpha)$ of 0.45 . Analysis of the components of $\chi^{2}$ gave a value of $X^{2}=10.57$; $P<0.001$ for heterogeneity confirming the presence of significant genetic heterogeneity in this cohort. Data on the conditional probability of linkage by pedigree is shown in
Table1. In pedigrees 1-4 a maximum multipoint lod score for linkage of 3.89 to the region D10S547 to D10S191 could be obtained by post hoc analysis. Pedigrees and haplotypes of four families not linked to chromosome10 are shown in Figure 1. In pedigrees6-8 definite exclusion of linkage was found for the region D10S547 to D10S191 and D10S197 with multipoint lod scores $<-5$.

Comparison of the clinical and biochemical features of Refsum's disease phenotype between the two groups of patients revealed no differences in clinical presentation manifest clinical symptoms, severity of disease and initial or post-treatment plasma phytanic acid concentration.

\section{Discussion}

Refsum's disease is a peroxisomal disorder associated solely with a deficiency of phytanic acid metabolism and can be caused by mutations in the PAHX gene which has been localised to the region D10S226 to D10S223. ${ }^{2-4}$ All but one case of Refsum's disease described to date have been found to be due to mutations in PAHX linked to these chromosome 10 loci, or not to complement cell lines from patients with Refsum's disease. The atypical case presented with classical features of Refsum's disease, but his fibroblasts complemented fibroblasts from patients with Refsum's disease and not those from patients with rhizomelic chondrodysplasia (RCDP). ${ }^{7}$

In our series of 17 cases in the UK, four pedigrees showed evidence of linkage to the region D10S547 to D10S191 where $\mathrm{PAHX}$ is located. This is consistent with previous reports and suggests a closer localisation of the PAHX gene between the markers D10S547 and D10S223. However, genetic heterogeneity was present, as $55 \%$ of the cohort did not show linkage to this region when evaluated at the best location for the group.

All these patients presented with a classical phenotype and could not be differentiated from the PAHX-linked group by clinical or biochemical criteria. However, the phenotype of Refsum's disease may be misleading as one consanguineous

Table 1 Two-point lod scores and heterogeneity analysis between chromosomes 10p loci and PAHX locus for 8 families with Refsum's disease

\begin{tabular}{|c|c|c|c|c|c|c|c|c|}
\hline \multirow[t]{2}{*}{ Marker } & \multicolumn{8}{|c|}{ Family } \\
\hline & 1 & 2 & 3 & 4 & 5 & 6 & 7 & 8 \\
\hline D10S249 & $-\infty$ & $-\infty$ & $-\infty$ & 0.000 & $-\infty$ & $-\infty$ & 0.727 & $-\infty$ \\
\hline D10S591 & -0.500 & 0.977 & $-\infty$ & 0.000 & $-\infty$ & $-\infty$ & 0.426 & 0.000 \\
\hline D10S189 & 0.500 & $-\infty$ & $-\infty$ & -0.109 & $-\infty$ & 0.852 & 0.301 & $-\infty$ \\
\hline D10S547 & $-\infty$ & 0.250 & 0.426 & 0.000 & -0.353 & $-\infty$ & 0.227 & $-\infty$ \\
\hline D10S191 & 0.500 & 1.579 & 1.931 & 0.125 & -0.329 & $-\infty$ & $-\infty$ & $-\infty$ \\
\hline D10S1653 & 0.250 & $-\infty$ & $-\infty$ & 0.000 & $-\infty$ & $-\infty$ & $-\infty$ & $-\infty$ \\
\hline D10S548 & 0.375 & -0.102 & 1.329 & 0.000 & -0.144 & $-\infty$ & $-\infty$ & $-\infty$ \\
\hline D10S197 & 0.625 & $-\infty$ & $-\infty$ & 0.125 & $-\infty$ & $-\infty$ & $-\infty$ & $-\infty$ \\
\hline Likelihood of linkage & 1.0 & 3.04 & 197.0 & 1.00 & 3.03 & 1.00 & 1.50 & 1.00 \\
\hline $\begin{array}{l}\text { Conditional probability of } \\
\text { linked type }\end{array}$ & 0.721 & 0.969 & 0.986 & 0.522 & 0.277 & $\varangle 0.001$ & $\lessdot 0.001$ & $\lessdot 0.001$ \\
\hline
\end{tabular}


Family 5

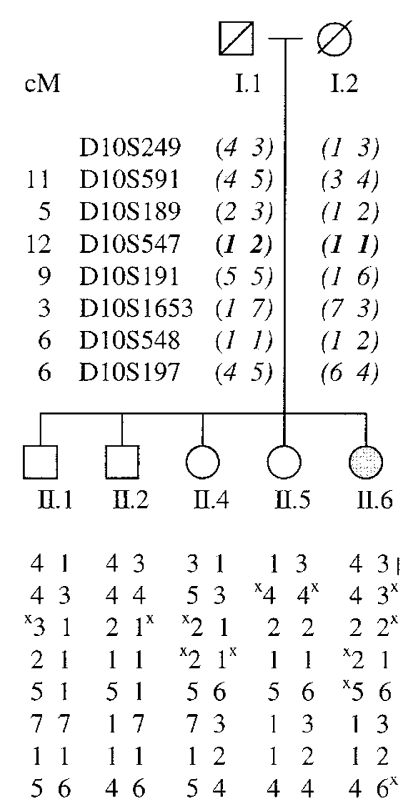

Family 6

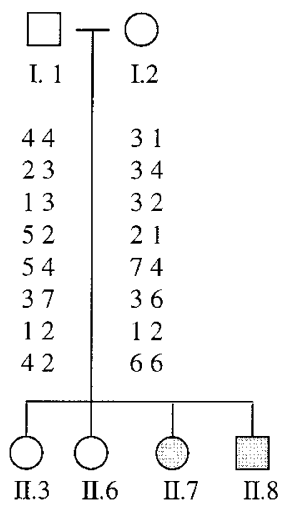

$\begin{array}{lllllllll}4 & 1 & 4 & 1 & 4 & 1 & 4 & 3\end{array}$

$\begin{array}{lllllll}2 & 4 & 3 & 4 & 2 & 4 & 2\end{array}$

$\begin{array}{lllllllll}1 & 2 & 3 & 2 & 1 & 3^{\mathrm{x}} & & 13\end{array}$

$\begin{array}{llllllll}5 & 1 & 2 & 1 & 5 & 2 & 5 & 1^{x}\end{array}$

$\begin{array}{llllllll}5 & 4 & 4 & 4 & 5 & 7 & x_{4} & 4\end{array}$

$\begin{array}{llllllll}3 & 6 & x_{3} & 6 & 3 & 3 & 7 & 6\end{array}$

$\begin{array}{llllllll}1 & 2 & 1 & 2 & 1 & 1 & 2 & 2\end{array}$

$\begin{array}{llllll}46 & 46 & 46 & 26\end{array}$
Family 7

Family 8

Figure 1 Pedigrees and genotype data for markers spanning the PAHX candidate gene locus between D10S457 and D10S191 for four families with a Refsum's disease phenotype not linked to chromosome 10. Genetic distances between the markers are indicated. Deduced genotypes are shown in italics and brackets. Sites of likely meiotic recombination are marked with $\mathrm{x}$. Dead or missing sibs are excluded from pedigrees with haplotypes for clarity: in family 5 one affected dead sib (II.3) has been excluded; in family 6 two dead unaffected (II.1 and II.4) and one dead affected (II.5) sibs have been excluded and one sib (II.2) could not be located. Parents in family 7 are consanguineous through a first cousin marriage.

family has been described with an atypical Refsum's disease phenotype but linked genetically to the PAHX region.8, Atypical clinical and biochemical features included leukodystrophy and pipecolic acidaemia which are features of generalised peroxisomal assembly disorders presenting as the continuum between Zellweger's syndrome and infantile Refsum's disease (IRD) but not of the complementation group which includes Refsum's disease. ${ }^{10}$

Our results show that Refsum's disease is genetically heterogeneous with $55 \%$ of cases likely to be caused by mutations in genes other than PAHX. Taking our results and those of the other atypical cases, the clinical phenotypic and genetic data suggests that the constellation of features termed Refsum's disease are not homogeneous and, in common with other peroxisomal diseases, ${ }^{10}$ are more likely to represent a syndrome with multiple causes rather than a monogenic disorder.

\section{Acknowledgements}

This study was supported by grants from the Special Trustees of both the Chelsea and Westminster and St Thomas' Hospitals.

\section{References}

1 Steinberg D: Refsum Disease. In: Scriver CR, Beaudet AL, Sly WS, Valle D (eds). The M etabolic and M olecular Bases of Inherited Disease, 7th edn. McGraw Hill: New York, 1995, pp 2351-2369.
2 Jansen GA, Ofman R, Ferdinandusse $\mathrm{S}$ et al: Refsum disease is caused by mutations in the phytanoyl-CoA hydroxylase gene. Nat Genet 1997; 17: 190-193.

3 Mihalik SJ, Morrell JC, Kim D, Sacksteder KA, Watkins PA, Gould S): Identification of PAHX, a Refsum disease gene. Nat Genet 1997; 17: 185-189.

4 Jansen GA, Ferdinandusse S, Skjeldal OH et al: Molecular basis of Refsum's disease: identification of new mutations in the phytanoyl-CoA hydroxylase cDNA. J Inher Metab Dis 1998; 21: 288-291.

5 Krugylak L, Daly MJ, Reeve-Daly MP, Lander ES: Parametric and non-parametric linkage analysis: a unified multipoint approach. Am J Hum Genet 1996; 59: 1347-1363.

6 Terwilliger JD, Ott J: Handbook of Human Genetic Linkage. Johns Hopkins University Press: Baltimore, 1994.

7 Moser AB, Rasmussen M, Naidu Set al: Phenotype of patients with peroxisomal disorders sub-divided into sixteen complementation groups. J Pediatr 1995; 127: 13-22.

8 Tranchant C, Aubourg P, Rocchiccioli F, Warter JM: A new peroxisomal disease with impaired phytanic acid and pipecolic acid oxidation. Neurology 1993; 43: 2044-2048.

9 Nadal N, Rolland M-O, Tranchant C et al: Localisation of Refsum disease with increased pipecolic acidaemia to chromosome 10p by homozygosity mapping and carrier testing in a single nuclear family. Hum Mol Genet 1995; 4: 1963-1966.

10 Powers JM, Moser HW: Peroxisomal disorders: genotype, phenotype, major neuropathologic lesions and pathogenesis. Brain Pathol 1998; 8: 101-120. 